\title{
A Proposed Model of Household Waste Separation Behavior: Pilot Test and Instrument Validation
}

\author{
Syukrie Mohd Nasir ${ }^{1 *}$, Haryati Shafii ${ }^{1}$, Azlina Md Yassin ${ }^{1}$
}

${ }^{1}$ Faculty of Technology Management and Business

Universiti Tun Hussein Onn Malaysia, Batu Pahat, 86400, MALAYSIA

*Corresponding Author

DOI: https://doi.org/10.30880/jstard.2021.03.01.005

Received 3 March 2021; Accepted 16 May 2021; Available online 15 June 2021

\begin{abstract}
Due to the increasing waste generation over the years in Malaysia, there is an urgent need to address this problem by implementing effective household waste separation initiatives. Although past studies have tried to explain the waste behavior from psychological perspective, there is little understanding as to the impact of environmental ethics and specific waste separation knowledge towards waste separation behavior. The aims of this article are to present questionnaire development based on waste separation behavior proposed model, pre-test, pilot test and findings. After obtaining 116 valid questionnaires from households in the district of Mersing, Johor, descriptive and factor analysis were conducted. The results from pilot test indicated that both specific waste separation knowledge and waste separation at source behavior were moderate. Early findings indicate that most of households reject the anthropocentric and technocentric ethics orientation. From the factor analysis, it can be concluded that the proposed model intended to predict SAS behavior warrant minor amendments which enable the model to be used in the future study. The valid and reliable instrument has a potential to better understand the underlying SAS behavior among households in Malaysia.
\end{abstract}

Keywords: Separation at source behavior; Environmental ethics; Specific waste separation knowledge; Personal norm; Instrument validation

\section{Introduction}

Separation of waste at the source (SAS) is a process of categorizing and then separating waste according to its type. SAS is a step that needs to be taken before the waste undergoes a recycling process or is disposed of with appropriate methods according to the type of waste. If the waste is not separated properly, the amount of waste that will be sent to the landfill will increase hence increasing the environmental pollution caused by the landfill. Therefore, since SAS is intended to minimize harm to the environment, it can be categorized as pro-environmental behavior [1]. In Malaysia, landfill is the main method to dispose waste. However, the actual amount of waste that can be recycled but sent to landfills is high indicating that some Malaysians do not separate their waste [2]. In this regard, the government through National Solid Waste Management Department under the Ministry of Housing and Local Government has made it compulsory for waste separation among households. This obligation is mandated under Act 672 and the state of Johor is among the states that have adopted the act.

Past studies have been conducted to determine why some individuals separate waste and others do not. Among the factors that have been studied include technical, management and legal as well as psychological. Many studies through the psychological perspective have employed factors such as values, attitudes, and intentions in determining SAS behavior [3], [4]. However, the aspect of environmental ethics has not been given enough attention from researchers [5]. In theory, environmental ethics can influence individual behavior particularly pro-environmental behaviors [6]. Knowledge factors are also often used by researchers to determine individual pro-environmental behavior [7], [8]. However, the knowledge factor that have been employed in those studies is general environmental knowledge and general waste management knowledge. Study of specific knowledge on SAS behaviors was still lacking which warrant further investigation in this study. 
Accordingly, a proposed model for predicting the influence of environmental ethics and specific knowledge on SAS has been developed for this study. The proposed model has adapted and modified the Value-Belief-Norm (VBN) model introduced by Stern et al., [9]. The VBN model suggests that values that an individual hold will influence belief and further influence personal norms that ultimately influence individual behavior through a chain of cause and effect. Through the proposed model, it is predicted that environmental ethics measured through its four dimensions (anthropocentric, technocentric, biocentric and ecocentric) will influence personal norms which in turn influence SAS behavior. Specific knowledge of waste separation is predicted to influence the strength of the relationship between personal norm and SAS behavior. Therefore, specific knowledge will be included in the study as the moderator variable for the relationship.

\section{Materials and Method}

Specifically, the objective of this study is to develop a validated questionnaire. Measurement items for the study were developed based on previous literatures. The measurement items were adapted and later modified accordingly to ensure appropriateness with Malaysian context. Most of the items in the study were adapted items from validated past questionnaires while the remaining were constructed based on theories and guidelines.

Table 1 - Constructs and sources

\begin{tabular}{|c|c|c|}
\hline Constructs & Number of items & Sources \\
\hline Anthropocentric & 5 & $\begin{array}{l}\text { Thompson and Barton [18], } \\
\text { Domanska [26] }\end{array}$ \\
\hline Technocentric & 5 & $\begin{array}{l}\text { Gladwin et al., [25], } \\
\text { Whyte and Lamberton [27] }\end{array}$ \\
\hline Biocentric & 5 & $\begin{array}{l}\text { Palmer [28], } \\
\text { Taylor [29] }\end{array}$ \\
\hline Ecocentric & 5 & $\begin{array}{l}\text { Thompson and Barton [18], } \\
\text { Bosselmann [30] }\end{array}$ \\
\hline Personal norm & 7 & $\begin{array}{l}\text { Stern et al., [9], } \\
\text { Steg et al., [31], } \\
\text { Chua et al., [32] }\end{array}$ \\
\hline Specific SAS knowledge & 10 & $\begin{array}{l}\text { Developed for this study based on } \\
\text { SAS guideline by National Solid } \\
\text { Waste Management Department }\end{array}$ \\
\hline SAS behavior & 10 & $\begin{array}{l}\text { Developed for this study based on } \\
\text { SAS guideline by National Solid } \\
\text { Waste Management Department }\end{array}$ \\
\hline
\end{tabular}

Table 1 shows each construct, the number of items according to the construct and the sources of the construct. All items in the construct are measured with Likert scale. Likert scale is the most popular measurement technique in the social science research [10] and is the most frequently used approach to measure various types of constructs. By using the scale, respondents will be able to express approval or disapproval of the object to be measured. This study applies even numbered scales to avoid central tendency error [11], [12]. This type of error can occur especially in the context of studies in Asian countries when respondents often choose a midpoint or neutral in expressing their choice of views [13]. Since most of the measurement items constructed for this study adapted sources from outside Malaysia with English as the original language, it was first translated into Bahasa Malaysia which is the common language of communication in this country. This process is important to avoid errors that may arise from language and cultural differences [14]. Some researchers suggest the method of back translation because it is the most frequently used [15], which is employed in this study.

\subsection{Demographic Variables}

Demographics variables for the study include households' gender, age, level of education and sector of occupation.

\subsection{Independent Variables}

Environmental ethics with its four dimensions (anthropocentric, technocentric, biocentric and ecocentric) were set for independent variables. All four dimensions was measured by 5 items respectively. For example, "Humans have the right to change nature to meet their own needs and human progress" is used to measure anthropocentric ethics, "Through Science and technology, our problems with pollution and diminishing resources can be resolved" is used to measure 
technocentric ethics, "We must live in harmony with other species on this earth" is used to measure biocentric ethics and "Humans are part of earth community which consists of various species of plants and animals and also ecosystem" is used to measure ecocentric ethics. The 4-points Likert-scale ranging from 1 to 4, representing "strongly disagree", "disagree", "agree" and "strongly agree", was used for respondents to rate each item. Higher scores reflect support towards respective environmental ethics.

\subsection{Mediating Variable}

Personal norm was set for mediating variable since it is predicted that the relationship between environmental ethics dimensions towards SAS behavior will be mediated by this variable. Personal norm towards waste separation was measured by 7 items reflecting individual household norm towards waste separation behavior. For instance, "I would feel guilty if I didn't separate the waste properly" and "I am convinced that waste separation is my responsibility and not the responsibility of the cleaning contractors or anyone else". Each item was scored on a 4-points Likert-scale namely "strongly disagree", "disagree", "agree" and "strongly agree". Higher scores reflect a more positive personal norm towards separation behavior.

\subsection{Dependent Variable}

The dependent variable for the proposed model is SAS behavior. SAS behavior was measured by separating frequency of ten different types of waste (according to the guideline by the National Solid Waste Management Department) which are (i) paper (boxes, cardboards and newspapers), (ii) plastic (plastic bags, plastic bottles, plastic containers), (iii) glass/ ceramic (broken vases and plates), (iv) metal/ steel/ aluminum (cans and kitchen utensils), (v) electronic (batteries, light bulbs and small electrical appliances), (vi) leather/ rubber/ fabric (shoes, gloves and bags), (vii) hazardous (aerosol cans, poison cans and paint bottles), (viii) garden/ farm (leaves, branches and flowers), (ix) bulky (broken beds, sofas and big electrical appliances) and (x) kitchen and contaminated (food waste, contaminated materials and disposal diapers). Each item was scored on a 4-point Likert-scale namely "never", "rarely", "sometimes", and "always".

\subsection{Moderator Variable}

Specific waste separation knowledge was set for the moderating variables and measured by 10 items reflecting level of specific knowledge regarding waste separation. For example, "I know the proper way to separate hazardous waste". Each item was measured on a 4-points Likert-scale namely "strongly disagree", "disagree", "agree" and "strongly agree". Higher scores reflect respondent is knowledgeable towards respective knowledge.

\subsection{Organization of Questionnaire Items}

The proposed model for this study consists of 7 latent variables namely: anthropocentric, technocentric, biocentric, ecocentric, personal norm, specific waste separation knowledge and separation at source behavior. To measure all those 7 variables, the questionnaire was divided into 5 sections namely: Demographic (Section A); SAS behavior (Section B); SAS knowledge (Section C); Personal norm (Section D); and Environmental ethics (Section E). After completing the demographic section, respondent will have to answer the waste separation behavior first before answering other items in the questionnaire. The purpose is to ensure that respondent will not guess on how to answer the dependent variable (separation behavior) after going through the rest of independent variable items in the questionnaire. This is also to reduce respondent bias as stated by Parkhe [16], where respondent guessing the relationship between predictor and criterion variables and consciously matching their responses to the two measures.

\section{Pre-test, Pilot test and Results}

\subsection{Pre-testing Stage}

Pre-testing of the research instrument was carried out to obtain the views of field experts and from the respondents prior to instrument distribution to the respondents at the later stage (pilot test). Overall, this study has obtained views from 2 faculty experts, 1 officer from National Solid Waste Management Department, 1 officer from Southern Waste Management Sdn. Bhd. (SWM) and 2 members of the public. During the pre-test, the individuals referred will examine the items and provide their comments and views. Several improvements to the study instrument have been made after taking into account the views and comments. Among the comments that have been received were: measurement items were suitable to measure the proposed variables, number of items in the instrument are too many; suitability of items through Likert scale with even or odd number; and to whom the questionnaire was addressed should be clearly stated. Accordingly, several improvements have been made to the research instrument including: stated clearly in the main page of the questionnaire that the respondents of the study are those who are usually responsible for managing waste at home (can be head of the family or housewife); and the choice of Likert scale with even number of options. As such, at this point it can be concluded that the instrument has met face validation criteria where all the constructed measurement items 
really measured the intended variables. For comments regarding number of items in the questionnaire, it will be explained in the pilot test section later.

\subsection{Pilot Test and Results}

The pilot test conducted has 3 objectives: to ensure that each measurement item truly measures the relevant construct; determine the internal consistency of each item in the construct and; determine whether respondents understand the questions asked through questionnaire items. Pilot test for this study was conducted using convenience sampling method and was administered to households in the district of Mersing, Johor. The district of Mersing has been selected for the pilot study as the main study will be conducted in Kluang district. In this regard, the selection of Mersing district which is adjacent to Kluang district has 2 goals: to avoid the same respondents to answer the questionnaire in the main study and; District of Mersing has a respondent with characteristics that are similar to Kluang. The pilot study was administered online with the help of Mersing SWM officer. A month after the questionnaire was sent to selected households through email (with link to the online questionnaire), the total number of respondents who answered the questionnaire was 119. However, a total of 3 responses were excluded due to answering 4 (highest point score) for all items and answering 1 (the lowest point score) for all items. Accordingly, a total of 116 responses were selected for further analysis $(\mathrm{N}=116)$. Data from the pilot test were analyzed using SPSS. Table 2 shows the demographic profile of the respondent.

Table 2 - Demographic profile $(\mathrm{N}=116)$

\begin{tabular}{|c|c|c|}
\hline Demographic variable & Sub-group & Percentage (\%) \\
\hline \multirow[t]{2}{*}{ Gender } & Male & 29.3 \\
\hline & Female & 70.7 \\
\hline \multirow[t]{8}{*}{ Age (years) } & $20-25$ & 7.8 \\
\hline & $26-30$ & 2.6 \\
\hline & $31-35$ & 3.4 \\
\hline & $36-40$ & 5.2 \\
\hline & $41-45$ & 22.4 \\
\hline & $46-50$ & 22.4 \\
\hline & $51-55$ & 5.2 \\
\hline & $>55$ & 31 \\
\hline \multirow[t]{9}{*}{ Level of education } & No formal education & 5.2 \\
\hline & Primary school & 12.1 \\
\hline & PMR/ SRP & 4.3 \\
\hline & SPM/ SVM & 35.3 \\
\hline & STPM/ STAM & 16.4 \\
\hline & Diploma & 10.3 \\
\hline & Bachelor Degree & 7.8 \\
\hline & Master Degree & 6.9 \\
\hline & $\mathrm{PhD}$ & 1.7 \\
\hline \multirow[t]{5}{*}{ Sector of occupation } & Self-employed/ & 22.4 \\
\hline & business & 50 \\
\hline & Government & 14.7 \\
\hline & Private & 12.9 \\
\hline & Not working & \\
\hline
\end{tabular}

Approximately $70.7 \%$ of respondents are female. The majority of the respondents' age (31\%) are above 55 years. The respondents are mainly SPM/ SVM holder (35.3\%), while 5.2 \% of them have received no formal education. Last but not least, half of the respondent are working with the government agencies followed by $22.4 \%$ of respondent are self-employed. It can be expected that most of the respondent are housewives and they are responsible for managing waste disposal at home. 
Table 3 - Descriptive statistic of specific knowledge

\begin{tabular}{llllll}
\hline $\begin{array}{c}\text { Specific } \\
\text { knowledge }\end{array}$ & N & Minimum & Maximum & Mean & S. D \\
\hline Know-how & $\mathbf{1 1 6}$ & 1 & 4 & 2.23 & .690 \\
Type & $\mathbf{1 1 6}$ & 1 & 4 & 2.29 & .560 \\
Recyclable & $\mathbf{1 1 6}$ & 1 & 4 & 2.24 & .654 \\
Collection & $\mathbf{1 1 6}$ & 1 & 4 & 2.22 & .647 \\
Kitchen waste & $\mathbf{1 1 6}$ & 1 & 4 & 2.21 & .583 \\
Garden waste & $\mathbf{1 1 6}$ & 1 & 4 & 2.34 & .659 \\
Bulky waste & $\mathbf{1 1 6}$ & 1 & 4 & 1.58 & .952 \\
Hazardous & $\mathbf{1 1 6}$ & 1 & 4 & 1.50 & .899 \\
Need cleaning & $\mathbf{1 1 6}$ & 1 & 4 & 2.25 & .868 \\
Info through & $\mathbf{1 1 6}$ & 1 & 4 & & .617 \\
media & & & & & \\
\hline
\end{tabular}

The descriptive statistical analyses for specific knowledge moderator variable are shown in Table 3 . The mean of most of the items are relatively moderate, indicating that the majority of the households only have moderate specific knowledge on waste separation. Important point to be highlighted here is specific knowledge on how to separate bulky waste, hazardous waste and that certain waste need cleaning are relatively low. Respondents moderately agree that they received most of the information about waste separation through media. Standard deviation values are less than 1 indicates that all variables are relatively concentrated around the means.

Table 4 - Descriptive statistic of SAS behavior

\begin{tabular}{llllll}
\hline $\begin{array}{c}\text { Type of } \\
\text { waste }\end{array}$ & N & Minimum & Maximum & Mean & S. D \\
\hline Paper & 116 & 1 & 4 & 2.53 & .879 \\
Plastic & 116 & 1 & 4 & 3.03 & .645 \\
Glass & 116 & 1 & 4 & 3.01 & .704 \\
Metal & 116 & 1 & 4 & 3.02 & .604 \\
Electrical & 116 & 1 & 4 & 2.18 & .776 \\
Fabric & 116 & 1 & 4 & 2.12 & .674 \\
Hazardous & 116 & 1 & 3 & 2.09 & .598 \\
Garden & 116 & 1 & 3 & 2.12 & .621 \\
Bulky & 116 & 1 & 3 & 2.10 & .690 \\
Kitchen & 116 & 1 & 4 & 3.18 & .717 \\
\hline
\end{tabular}

With regard to SAS behavior, the descriptive statistical analyses are shown in Table 4.4 items are relatively high (above 3.0), indicating that the majority of the households frequently separate plastic, glass, metal and kitchen waste. Kitchen waste is the most separated waste maybe due to it is easier to separate compared to other type of waste. Hazardous, garden and bulky waste are less frequently separated by the households. Standard deviation values are less than 1 indicates that all variables are relatively concentrated around the means.

Table 5 - Descriptive statistic of environmental ethics

\begin{tabular}{cccccc}
\hline $\begin{array}{c}\text { Dimension of } \\
\text { environmental } \\
\text { ethics }\end{array}$ & $\mathbf{N}$ & Minimum & Maximum & Mean & S. D \\
\hline Anthropocentric & 116 & 5.00 & 20.00 & 11.6897 & 5.25591 \\
Technocentric & 116 & 5.00 & 20.00 & 11.5603 & 5.25901 \\
Ecocentric & 116 & 5.00 & 20.00 & 13.4569 & 5.09628 \\
Biocentric & 116 & 5.00 & 20.00 & 13.1983 & 4.97510 \\
\hline
\end{tabular}

Environmental ethics was measured with its four dimensions; the descriptive statistical analyses is shown in Table 5. Most of respondents are more towards ecocentric ethics orientation with the highest mean (13.45) followed by biocentric ethics (13.19). This early finding indicates that most of households reject the anthropocentric and technocentric ethics which regard human as more superior than other living beings and environmental problem can be resolved through advancement in technology. This also in line with the idea that ecocentric and biocentric people will be more likely to conduct pro-environmental behavior as shown in the analysis of SAS behavior (moderate to high SAS behavior). 


\subsection{Instrument Validation with Factor Analysis}

Test of instrument validity was conducted with Factor Analysis using principal component analysis (PCA) in SPSS. The purpose was to investigate that all measurement items intended to measure respective constructs were really measuring the desired construct. In other words, all items within the extracted component or factor are correlated and associated to the construct. As stated by Churchill [17] to analyze construct validity of a measure we must determine "the extent to which the measure correlates with other measures designed to measure the same thing". According to Thompson [18], factor analysis can be broken down into three stages namely: PCA, exploratory factor analysis (EFA) and, confirmatory factor analysis (CFA). The earliest stage is to conduct PCA, followed by EFA and then analyze the findings of the factor solution using CFA. Accordingly, PCA was conducted to reduce a pool of measurement items into a smaller number of components [19]. However, EFA and CFA stages will only be conducted through findings from main study. Since the main study has not been carried out, EFA and CFA will not be reported in this article. Therefore, the implementation of PCA also addressed the issue of not using too many measurement items in the questionnaire (as recommended by faculty expert during the pretest phase).

The data from pilot study were tested to ensure they met the requirements for PCA using the Kaiser-Meyer-Olkin measure of Sampling Adequacy and Bartlett's test of Sphericity. For the PCA, an oblique rotation was chosen because it was anticipated that the underlying components (from items intended to measure environmental ethics and personal norm) would be related. Hence, Promax rotation method was employed which provide solutions with correlated components [19]. According to Comrey \& Lee [20], cut-off threshold for the factor loading above 0.63 can be considered very good. The number of components was determined using the PCA and Cronbach's $\alpha$ was calculated to evaluate internal consistency.

Table 6 - KMO and Bartlett's test

\begin{tabular}{lll}
\hline \multicolumn{2}{l}{ Kaiser-Meyer-Olkin Measure of Sampling Adequacy } & .948 \\
Bartlett's Test of Sphericity & Approx. Chi-Square & 4105.268 \\
& df & 351 \\
& Sig. & .000 \\
\hline
\end{tabular}

Table 6 and Table 7 summarizes the result of the PCA. The Kaiser-Meyer-Olkin (KMO) Measure of Sampling Adequacy was 0.948 and the Bartlett's Test of Sphericity was significant ( $p$-value $=0.000$ ) indicated that the sample size and the data obtained from the pilot study were adequate for conducting PCA. The highest and lowest communalities were 0.911 and 0.535 respectively. A total of four components (factors) were extracted based on Eigenvalue extraction (value more than 1.00), with $82.310 \%$ of total variance explained.

The PCA has grouped all biocentric ethics items into Component 1, all personal norm items into Component 3, and all ecocentric ethics into Component 4. However, all items for anthropocentric ethics and technocentric ethics load into Component 2. The factor loading of all items into respective components were higher than 0.6 indicating very good level of loading.

Table 7 - Result of PCA with internal consistency reliability

\begin{tabular}{|c|c|c|c|c|c|}
\hline $\begin{array}{l}\text { Comp } \\
\text { Item }\end{array}$ & 1 & 2 & 3 & 4 & Cronbach Alpha \\
\hline BIO1 & .904 & & & & .974 \\
\hline $\mathrm{BIO} 2$ & .937 & & & & \\
\hline $\mathrm{BIO} 3$ & .895 & & & & \\
\hline $\mathrm{BIO} 4$ & .939 & & & & \\
\hline BIO5 & .941 & & & & \\
\hline ANT1 & & .786 & & & .972 \\
\hline ANT2 & & .793 & & & \\
\hline ANT3 & & .795 & & & \\
\hline ANT4 & & .780 & & & \\
\hline ANT5 & & .805 & & & \\
\hline TEC1 & & .945 & & & \\
\hline TEC2 & & .927 & & & \\
\hline TEC3 & & .935 & & & \\
\hline TEC4 & & .940 & & & \\
\hline TEC5 & & .935 & & & \\
\hline PN1 & & & .729 & & .927 \\
\hline PN2 & & & .896 & & \\
\hline PN3 & & & .867 & & \\
\hline PN4 & & & .812 & & \\
\hline
\end{tabular}




\begin{tabular}{llll}
\hline PN5 & .894 & & \\
PN6 & .863 & & \\
PN7 & .822 & .944 & .967 \\
ECO1 & & .910 & \\
ECO2 & & .918 & \\
ECO3 & & .929 \\
ECO4 & & .930 \\
ECO5
\end{tabular}

\subsection{Reliability}

As shown in Table 7, the Cronbach's Alpha from the pilot test ranges from 0.927 to 0.974 and demonstrated high reliability [21], [22]. The widely-accepted cut-off is that alpha should be higher than 0.70 [23]. As of now, it can be concluded that the measurement instrument is valid and reliable to be used for future study where full dataset from the main study will be analyzed with structural equation modelling (SEM) analysis. Under SEM, the internal consistency reliability would be further analyzed using composite reliability (CR), as a comparison to the Cronbach's Alpha value.

\section{Discussion and Conclusion}

Firstly, PCA besides EFA and CFA should be performed in any social science study to ensure that measurement items as much as possible can be reduced or grouped into appropriate components. The PCA findings from the study show that measurement items aimed at measuring latent anthropocentric and technocentric variables are grouped together into component 2. Since all measurement items aimed at measuring biocentric, ecocentric and personal norms remain in their original group, the new components generated through PCA will maintain the original names of the variables namely biocentric, ecocentric and personal norm. However, for component 2, it will be renamed as anthro-techno ethics. The grouping of anthropocentric and technocentric measurement items is in line with Warren [24] which stated that technocentric can be view as similar to anthropocentric. According to Gladwin et al., [25], technocentric view humankind are separated from the natural world, the decision-making process is anthropocentric and based on economic implications, and economic development and technological progress can resolve problems resulting from environmental degradation.

Secondly, this article would like to suggest that, if possible, procedural measures to overcome respondent bias or common method bias be taken from the initial stage of the study to ensure that the data obtained are free from bias. This study, for example, has taken a procedural step by arranging the dependent variable items first in the questionnaire to prevent respondents from guessing the relationship between the variables and matching their answers based on the guess.

Thirdly, it is crucial to agree that the pre-test stage is very important as the earliest step before any social science study is done. Through pre-tests, opinions and comments received from experts in the field are very helpful in determining that all the measurement items which were obtained from the theory and previous questionnaires are suitable for use in a study. Pre-test also helps in face validity, and the appropriateness of sentences and structure of the measurement items. Any errors such as spelling, or unclear instructions can be identified and corrected from this pre-test stage.

Finally, as a conclusion, early findings from the study has shown that SAS behavior among households are moderate except for plastic, glass, metal and kitchen waste which are found to be more frequently separated. Majority of the households only have moderate specific knowledge on waste separation with specific knowledge on how to separate bulky waste, hazardous waste and that certain waste need cleaning are relatively low. Analysis also discovered most of households reject the anthropocentric and technocentric ethics belief. In addition, the article has clearly explained all the processes and stages starting from the formation of questionnaire items, pre-test and pilot test, and data analysis to items reduction using PCA. It can be concluded that the proposed model intended to predict SAS behavior warrant minor amendments which enable the model to be used in the future study.

\section{Acknowledgement}

The author would like to thank Public Service Department of Malaysia (Jabatan Perkhidmatan Awam Malaysia) and Universiti Tun Hussein Onn Malaysia for supporting this research work.

\section{References}

[1] Kollmuss, A., \& Agyeman, J. (2002). Mind the gap: why do people act environmentally and what are the barriers to pro-environmental behavior?. Environmental Education Research, 8(3), 239-260

[2] Moh, Y., \& Manaf, L. A. (2017). Solid waste management transformation and future challenges of source separation and recycling practice in Malaysia. Resources, Conservation \& Recycling. 116, 1-14

[3] Yu, S., Lu, T., Qian, X., \& Zhou, W. (2018). Behavioral intention analysis of waste separation in China-case study of Hangzhou using theory of planned behavior. International Review for Spatial Planning and Sustainable Development, 6(3), 63-77 
[4] Xu, L., Ling, M., Lu, Y., \& Shen, M. (2017). Understanding household waste separation behaviour: Testing the roles of moral, past experience, and perceived policy effectiveness within the theory of planned behaviour. Sustainability, 9(4), 625

[5] Valliere, W. A., \& Manning, R. E. (1980). Environmental ethics and wilderness management: An empirical study. General Technical Report NE, 195

[6] Thompson, S. C. G., \& Barton, M. A. (1994). Ecocentric and anthropocentric attitudes toward the environment. Journal of Environmental Psychology, 14(2), 149-157

[7] Liao, C., \& Li, (2019). Environmental Education, Knowledge, and High School Students' Intention toward Separation of Solid Waste on Campus. International Journal of Environmental Research and Public Health, 16(9), 1659

[8] Desa, A.; Kadir, N.B.A.; Yusooff, F. (2011). A study on the knowledge, attitudes, awareness status and behaviour concerning solid waste management. Procedia Soc. Behav. Sci. 18, 643-648

[9] Stern, P. C., Dietz, T., Abel, T., Guagnano, G. A., \& Kalof, L. (1999). A value-belief-norm theory of support for social movements: The case of environmentalism. Human Ecology Review, 81-97

[10] Joshi, A., Kale, S., Chandel, S., \& Pal, D. K. (2015). Likert scale: Explored and explained. Current Journal of Applied Science and Technology, 396-403

[11] Bishop, G. F. (1987). Experiments with the middle response alternative in survey questions. Public Opinion Quarterly, 51(2), 220-232

[12] Kulas, J. T., \& Stachowski, A. A. (2009). Middle category endorsement in odd-numbered Likert response scales: Associated item characteristics, cognitive demands, and preferred meanings. Journal of Research in Personality, 43(3), 489-493

[13] Harzing, A. W., Brown, M., Köster, K., \& Zhao, S. (2012). Response style differences in cross-national research. Management International Review, 52(3), 341-363

[14] Tyupa, S. (2011). A theoretical framework for back-translation as a quality assessment tool. New Voices in Translation Studies, 7(1), 35-46

[15] Douglas, S. P., \& Craig, C. S. (2007). Collaborative and iterative translation: An alternative approach to back translation. Journal of International Marketing, 15(1), 30-43

[16] Parkhe, A. (1993). Strategic alliance structuring: A game theoretic and transaction cost examination of interfirm cooperation. Academy of Management Journal, 36(4), 794-829

[17] Churchill Jr, G. A. (1979). A paradigm for developing better measures of marketing constructs. Journal of Marketing Research, 16(1), 64-73

[18] Thompson, B. (2004). Exploratory and confirmatory factor analysis. American Psychological Association

[19] Matsunaga, M. (2010). How to Factor-Analyze Your Data Right: Do's, Don'ts, and How-To's. International Journal of Psychological Research, 3(1), 97-110

[20] Comrey, A. L., \& Lee, H. B. (1992). A first course in factor analysis. Psychology Press

[21] DeVellis, R. F. 1991. Scale development. Newbury Park, CA: Sage

[22] Nunnally, J. 1978. Psychometric theory. New York: McGraw-Hill

[23] Hair, J. F., Bush, R. F., \& Ortinau, D. J. (2003). Marketing research within a changing information environment. New York: McGraw-Hill

[24] Warren, K. J. (Ed.) (1994). Ecological feminism: Environmental Philosophies. Routledge: London, UK.

[25] Gladwin, T.N.; Kennelly, J.J.; Krause, T.S. Shifting paradigms for sustainable development: Implications for management theory and research. Acad. Manag. Rev. 1995, 20, 874-907.

[26] Domanska, E. (2010). Beyond anthropocentrism in historical studies. Historein, 10, 118-130.

[27] Whyte, P., \& Lamberton, G. (2020). Conceptualising Sustainability Using a Cognitive Mapping Method. Sustainability, 12(5), 1977.

[28] Palmer, C. (1997). Environmental Ethics. Santa Barbara, California: ABC--CLIO

[29] Taylor, P. W. (2011). Respect for nature: A theory of environmental ethics. Princeton University Press

[30] Bosselmann, K. (2004). In search of global law: the significance of the Earth Charter. Worldviews: Global Religions, Culture, and Ecology, 8(1), 62-75

[31] Steg, L., Dreijerink, L., and Abrahamse, W. (2005). Factors influencing the acceptability of energy policies: a test of VBN theory. Journal of Environmental Psychology, 25, 415-425

[32] Chua, K. B., Quoquab, F., Mohammad, J., \& Basiruddin, R. (2016). The mediating role of new ecological paradigm between value orientations and pro-environmental personal norm in the agricultural context. Asia Pacific Journal of Marketing and Logistics 